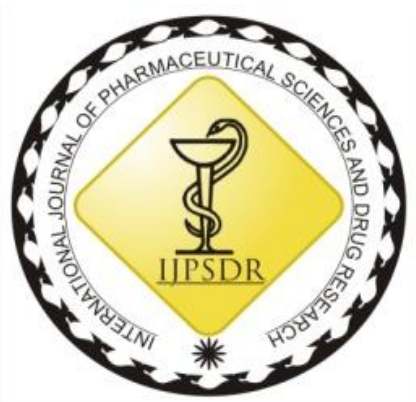

ISSN: 0975-248X

RESEARCH ARTICLE CODEN (USA): IJPSPP

$($ (c) $)$ EY-NC-SA

\title{
Development and Validation of RP-HPLC for Estimation of Neratinib in Bulk and Tablet Dosage Form
}

\author{
M Lakshmi Kanth*, B Raj Kamal \\ Mewar University, NH-79, Gangrar, Chhitorgarh-312901, Rajasthan, India
}

Copyright (C) 2019 M Lakshmi Kanth et al. This is an open access article distributed under the terms of the Creative Commons AttributionNonCommercial-ShareAlike 4.0 International License which allows others to remix, tweak, and build upon the work non-commercially, as long as the author is credited and the new creations are licensed under the identical terms.

\begin{abstract}
An accurate RP-HPLC method developed for the estimation of Neratinib in bulk and tablet dosage form. The method is and validated for parameters linearity, accuracy, suitability, specificity, precession, LOD, LOQ and robustness. An Altima column $(150 \mathrm{~mm} \times 4.6 \mathrm{~mm} \times 5 \mu)$ used for chromatographic separation within a runtime of 6 min. The mobile phase buffer (monopotassium phosphate) and acetonitrile $(60: 40 \mathrm{v} / \mathrm{v})$ with $0.1 \%$ formic acid is used. The flow rate maintained at $1.0 \mathrm{ml} / \mathrm{min}$ with the effluents monitored at $215 \mathrm{~nm}$. The Neratinib analyzed at retention time of 4.001 . The concentration linear over $30-180 \mu \mathrm{g} / \mathrm{ml}$ with regression equation $\mathrm{y}=6065.6 \mathrm{x}+795.43$ and regression coefficient 0.999 .
\end{abstract}

Keywords: Neratinib, antineoplastic activity, ICH Guidelines, method validation.

*Corresponding author: Mr. M. Lakshmi Kanth

Address: Mewar University, NH-79, Gangrar, Chhitorgarh-312901, Rajasthan, India

Tel.: +91-7675851984

E-mail $\bowtie$ : kanthmsc06@gmail.com

Relevant conflicts of interest/financial disclosures: The authors declare that the research was conducted in the absence of any commercial or financial relationships that could be construed as a potential conflict of interest.

Received: 29 January, 2019; Revised: 13 March, 2019; Accepted: 19 March, 2019; Published: 30 March, 2019

\section{INTRODUCTION}

Neratinib is 6, 7-disubstituted-4-anilinoquinoline-3carbonitrile that exhibits antineoplastic activity and acts as inhibitor of the HER-2. [1] Neratinib reduces auto phosphorylation in cells by binding to HER-2 receptor irreversibly. [2-3] Phase I examination of single agent Neratinib administration showed a $C_{\max }$ of 5.8-119 $\mathrm{ng} / \mathrm{mL}$ over a 40 to $400 \mathrm{mg}$ dose range. ${ }^{[4-7]}$ Chemically Neratinib is (E)-N-[4-[3-chloro-4-(pyridin-2-ylmethoxy) anilino]-3-cyano-7-ethoxyquinolin-6-yl]-4-(dimethyl amino)but-2-enamide with molecular formula $\mathrm{C}_{30} \mathrm{H}_{29} \mathrm{ClN}_{6} \mathrm{O}_{3}$ and molecular weight $557.051 \mathrm{~g} / \mathrm{mol}$ (Figure 1). Literature survey reveals that few UV Spectroscopy, fluorescence spectroscopy, HPLC and
LC-MS/MS methods [8-13] were developed for determination of Neratinib in both human plasma and pharmaceutical dosage forms. The present research is novel and validated as per ICH guidelines. [14]<smiles>CCOc1cc2ncc(C#N)c(Nc3ccc(OCc4ccccn4)c(Cl)c3)c2cc1NC(=O)/C=C/CN(C)C</smiles>

Fig. 1: Structure of Neratinib 


\section{MATERIALS AND METHODS}

Neratinib was kindly gifted from Hetero Drugs Ltd. Hyderabad. Commercially available NERLYNX ${ }^{\circledR}$ (Neratinib $4 \mathrm{mg}$ ) tablet procured from local market. Acetonitrile (Finar reagents), monopotassium phosphate and phosphoric acid (S D fine Chem limited), formic acid (Fisher scientific) were used without further purification.

Quantitative HPLC used is of Waters Alliance 2695 system with Empower-2 Software. An Altima column $(150 \mathrm{~mm} \times 4.6 \mathrm{~mm} \times 5 \mu)$ selected for elution of drug. The UV Spectrometer PG Instruments T60 used for analysis.

Preparation of Neratinib Standard Solution

About $0.012 \mathrm{~g}$ of Neratinib working standard accurately weighed into a $10 \mathrm{ml}$ standard flask. Contents dissolved in $7 \mathrm{ml}$ of diluent and sonicated for 25-30 minutes. The contents made up to the mark with diluents. This is considered as the stock solution.

Preparation of Neratinib Working standard

$10 \mathrm{ml}$ of prepared stock solution taken into $100 \mathrm{ml}$ volumetric flask, made up to mark with diluents to obtain Neratinib working standard of $120 \mu \mathrm{g} / \mathrm{ml}$.

\section{Preparation of Neratinib Sample}

Neratinib capsule powder weight equivalent to $12 \mathrm{mg}$ of Neratinib taken in $10 \mathrm{ml}$ volumetric flask. Diluents added till the mark and sonicated for 20-30 min and filtered. $1 \mathrm{ml}$ of stock solution taken into $10 \mathrm{ml}$ volumetric flask, made up to $10 \mathrm{ml}$ with diluents to produce $1200 \mu \mathrm{g} / \mathrm{ml}$.

\section{Preparation of Buffer}

The buffer prepared by mixing $1.36 \mathrm{~g}$ of monopotassium phosphate with $900 \mathrm{ml}$ of milli-Q water. Contents degassed and made up to $100 \mathrm{ml}$ volume with water. Phosphoric acid used to adjust the $\mathrm{pH}$ of contents to $3.0 .100 \mathrm{~mL}$ of formic acid mixed with $100 \mathrm{~mL}$ of water to obtain $0.1 \%$ formic acid.

\section{HPLC Conditions}

The solvent A comprises of $0.01 \mathrm{M}$ disodium hydrogen orthophosphate ( $\mathrm{pH}$ 3.0), Solvent B comprises of Acetonitrile with $0.1 \%$ formic acid. The contents mixed thoroughly, filtered through poly-tetra-fluoro ethanol (PTFE) filter of $0.45 \mu \mathrm{m}$ pore size. The contents degassed by sonication. The eluents monitored at $215 \mathrm{~nm}$ with a run time maintained at $6 \mathrm{~min}$. The column must be equilibrated for 25-30 min prior to the sample analysis.

\section{Analytical Method validation}

Method validation includes testing of system suitability, specificity, linearity, accuracy, precision and robustness of the method developed.

\section{Linearity}

The ability of developed procedure obtain test results proportional to concentration of sample is measured. The method is considered valid if the correlation coefficient $\left(\mathrm{r}^{2}\right)>0.998$. The linearity of Neratinib was evaluated for concentrations of $30-180 \mu \mathrm{g} / \mathrm{ml}$.

\section{Specificity}

The analysis results of samples spiked with impurities, degradation products were compared to the results of pure samples containing no impurities or degradation products to analyse the specificity of the developed HPLC method.

\section{System suitability}

The evaluation of area under curve, resolution, retention time, tailing factor and plate number was performing to check the system suitability. The \%RSD for system suitability parameter of Neratinib are within acceptable limit.

\section{Precision}

The intraday and interday precision of Neratinib standard and sample determined and results expressed in \%RSD to check the precision of developed method. The interday and intraday precession studies of Neratinib carried out at different concentrations (30, 90 and $150 \mu \mathrm{g} / \mathrm{ml}$ ) and results found within the acceptable limit

Limit of detection (LOD) and Limit of quantification (LOQ)

The LOQ and LOD of the developed method were evaluated by considering parameters like signal-tonoise ratio $(\mathrm{S} / \mathrm{N})$ and peak-to-peak ratio around the $\mathrm{RT}$ of Neratinib. The S/N ratio of 3 is accepted for LOD and a value of 10 is accepted for LOQ. The LOD (0.43 ppm) and LOQ (1.31 ppm) values of Neratinib were within the acceptable limit.

\section{Robustness}

The capacity of developed method to stay unaffected by minimal variations in method parameters is analysed. The samples analysed by varying different optimized parameters like detection wavelength, flow rate, injection volume and mobile phase composition. The effect of all these parameters determined.

\section{RESULTS}

\section{Linearity}

Five standard solutions of Neratinib of concentrations $30-180 \mu \mathrm{g} / \mathrm{ml}$ were injected and results tabulated (Table 1). A graph of concentration vs peak are plotted with slope of 6065.6, Y-intercept 795.4 and $\mathrm{r}^{2}$ (correlation coefficient) of 0.999. Regression equation of Neratinib was $y=6065.6 X+795.4$ (Figure 2).

\section{Specificity}

Specificity was tested by evaluating chromatogram of blank run and standard Neratinib (Figure 3,4). These showed that no peaks, interfering peaks or baseline noise was observed.

\section{System Suitability}

The system suitability of developed method was analyzed by injecting the Neratinib working standard six times. The suitability of method evaluated from percentage relative standard deviation of RT, USP plate count, peak area and USP tailing factor (Table 2). [14]

\section{Assay studies}

Six homogeneous samples of Neratinib sample and standard analysed. The \% assay of the Neratinib in the formulation estimated. The Neratinib sample and standard RT were similar i.e. 4.001. ${ }^{[10]}$ From Table 3, it was found that the method is linear for concentration 
$30-180 \mu \mathrm{g} / \mathrm{ml}$ for Neratinib. The \% assay of marketed Neratinib drug found to be $99.76 \%$ (Table 3).

Table 1: Calibration data of Neratinib

\begin{tabular}{ccc}
\hline Linearity Level $(\mathbf{\%})$ & Concentration $(\boldsymbol{\mu g} / \mathbf{m l})$ & Area \\
\hline 25 & 30 & 259635 \\
50 & 60 & 358945 \\
75 & 90 & 448155 \\
100 & 120 & 685499 \\
125 & 150 & 948512 \\
150 & 180 & 1099245 \\
\hline
\end{tabular}

Table 2: System suitability data of Neratinib

\begin{tabular}{|c|c|c|c|c|c|}
\hline S. No & $\begin{array}{l}\text { Name of the } \\
\text { drug \& conc } \\
(120 \mu \mathrm{g} / \mathrm{ml})\end{array}$ & $\begin{array}{c}\text { RT } \\
(\text { min) }\end{array}$ & Peak Area & $\begin{array}{l}\text { USP Plate } \\
\text { Count }\end{array}$ & $\begin{array}{l}\text { USP } \\
\text { Tailing }\end{array}$ \\
\hline 1 & Neratinib (std) & 4.001 & 730064 & 7325 & 1.69 \\
\hline 2 & Neratinib (std) & 4.002 & 723381 & 7386 & 1.68 \\
\hline 3 & Neratinib (std) & 4.003 & 721505 & 7291 & 1.69 \\
\hline 4 & Neratinib (std) & 4.004 & 720970 & 7243 & 1.68 \\
\hline 5 & Neratinib (std) & 4.008 & 726077 & 7254 & 1.69 \\
\hline 6 & Neratinib (std) & 4.013 & 719446 & 7602 & 1.67 \\
\hline Mean & & & 723574 & & \\
\hline Std. Dev. & & & 3912.1 & & \\
\hline \%RSD & & & 0.5 & & \\
\hline
\end{tabular}

Table 3: Assay data Neratinib

\begin{tabular}{ccc}
\hline Sample No & Retention time & \%Assay \\
\hline 1 & 4.001 & 99.89 \\
2 & 4.003 & 99.40 \\
3. & 4.008 & 99.44 \\
4. & 4.013 & 100.04 \\
5. & 4.004 & 100.16 \\
6. & 4.002 & 99.61 \\
Avg & 4.005 & 99.76 \\
SD & & 0.3166 \\
\%SD & & 0.32 \\
\hline
\end{tabular}

Table 4: Intra-day precision data of Neratinib

\begin{tabular}{cccc}
\hline Level & Low & Middle & High \\
\hline Concentration $(\boldsymbol{\mu g} / \mathbf{m l})$ & $\mathbf{3 0}$ & $\mathbf{9 0}$ & $\mathbf{1 5 0}$ \\
\hline Peak area Session 1 & 256985 & 445698 & 948565 \\
Session 2 & 263845 & 448756 & 958925 \\
Session 3 & 254416 & 458951 & 945698 \\
Avg. peak area & 258415.33 & 451135 & 951062.66 \\
SD & 4874.51 & 6939.39 & 6958.242 \\
\%RSD & 1.88 & 1.53 & 0.73 \\
\hline
\end{tabular}

Table 5: Inter Day precision data of Neratinib

\begin{tabular}{cccc}
\hline Level & Low & Middle & High \\
\hline Concentration $(\boldsymbol{\mu g} / \mathbf{m l})$ & $\mathbf{3 0}$ & $\mathbf{9 0}$ & $\mathbf{1 5 0}$ \\
\hline Peak area day 1 & 255894 & 446985 & 945845 \\
day 2 & 248556 & 458911 & 958589 \\
day 3 & 252697 & 455892 & 945289 \\
Avg. peak area & 252382.3 & 453929.3 & 949907.66 \\
SD & 3679.10 & 6200.51 & 7523.3 \\
\%RSD & 1.45 & 1.36 & 0.79 \\
\hline
\end{tabular}

\begin{tabular}{cccc}
\multicolumn{5}{c}{ Table 6: Accuracy data of Neratinib } \\
\hline S. No & Spiked level & \% Recovery & \% RSD \\
\hline 1 & $80 \%$ & 99.38 & \\
2 & $100 \%$ & 100.02 & 0.52 \\
3 & $120 \%$ & 98.99 & \\
\hline
\end{tabular}

\section{Precision}

Intra-day precession was performed for concentration levels $30 \mu \mathrm{g} / \mathrm{ml}, 90 \mu \mathrm{g} / \mathrm{ml}$ and $150 \mu \mathrm{g} / \mathrm{ml}$ within the same day at three different times session 1 , session 2 and session 3 .

Inter-day precision was carried by conducting at different concentration $30 \mu \mathrm{g} / \mathrm{ml}, \quad 90 \mu \mathrm{g} / \mathrm{ml}$ and $150 \mu \mathrm{g} / \mathrm{ml}$ level on three different days, using same homogeneous samples.

The \%RSD values for both inter-day and intra-day precision were found within acceptable limit. Results tabulated in Table 4 and Table 5.

\begin{tabular}{cc} 
Table 7: Robustness data of Neratinib & \\
\hline Parameter & \%RSD \\
\hline Flow Minus & 0.6 \\
Flow Plus & 0.5 \\
Mobile phase Minus & 0.4 \\
Mobile phase Plus & 0.6 \\
Temperature minus & 0.4 \\
Temperature plus & 0.5 \\
\hline
\end{tabular}

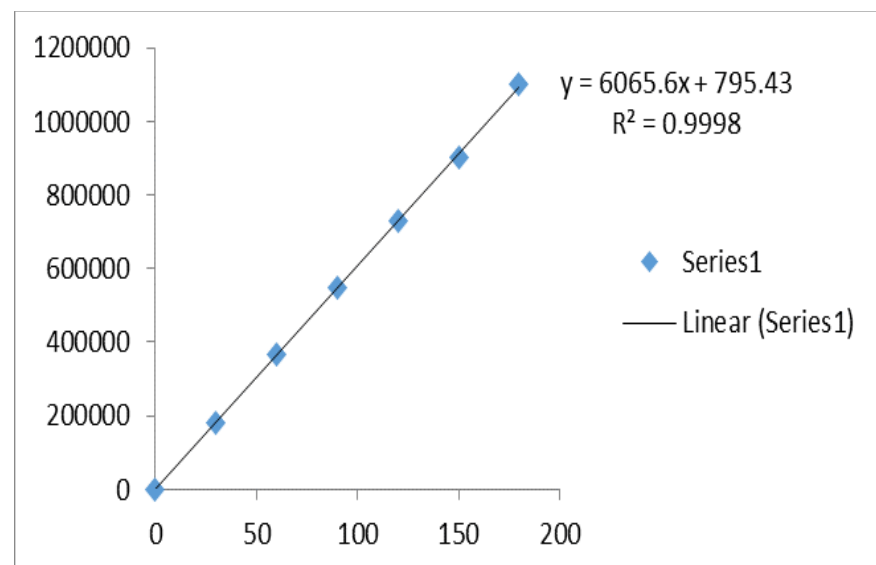

Fig. 2: Calibration Curve of Neratinib

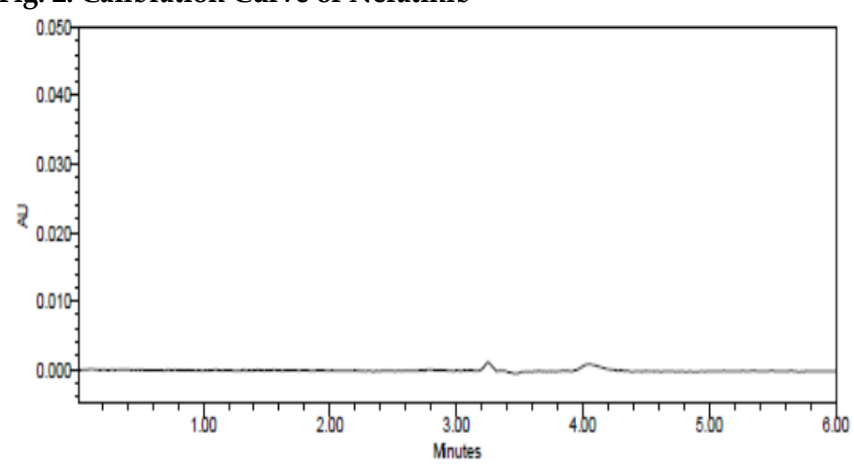

Fig. 3: Blank chromatogram

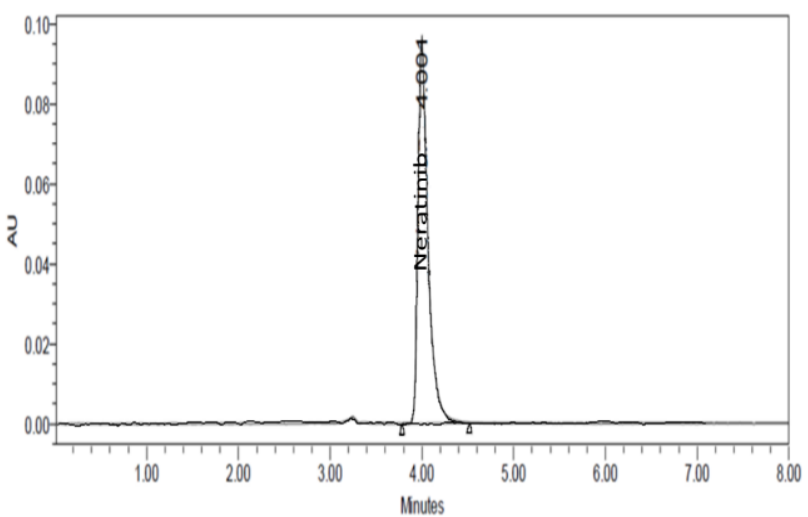

Fig. 4: Chromatogram of Neratinib standard 


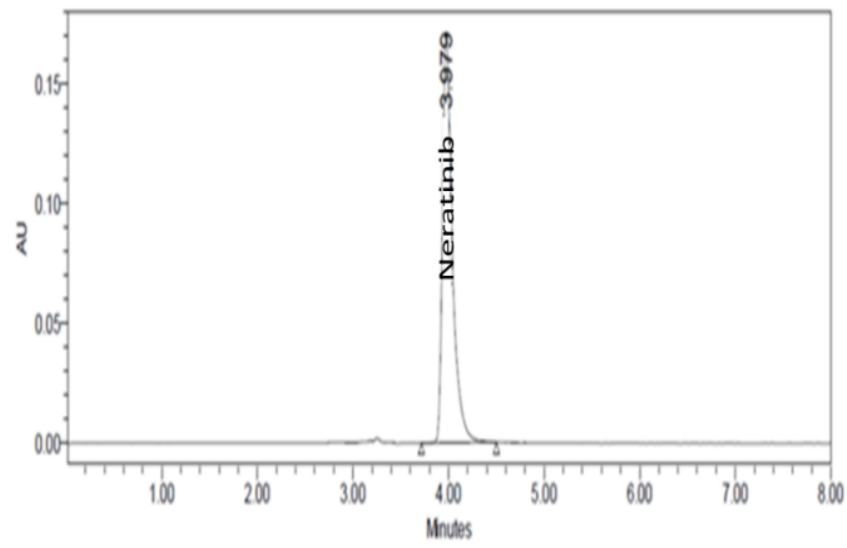

Fig. 5: Chromatogram of Neratinib sample

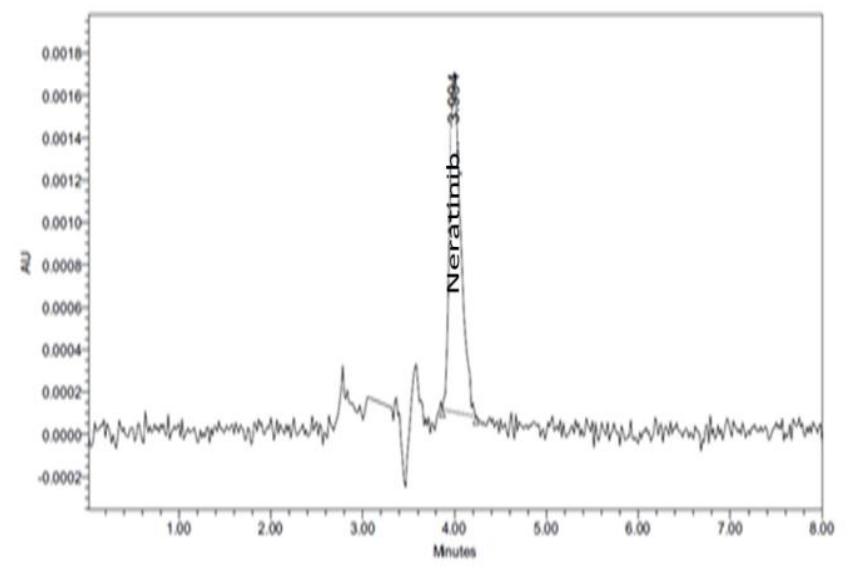

Fig. 6: LOD Chromatogram of Neratinib

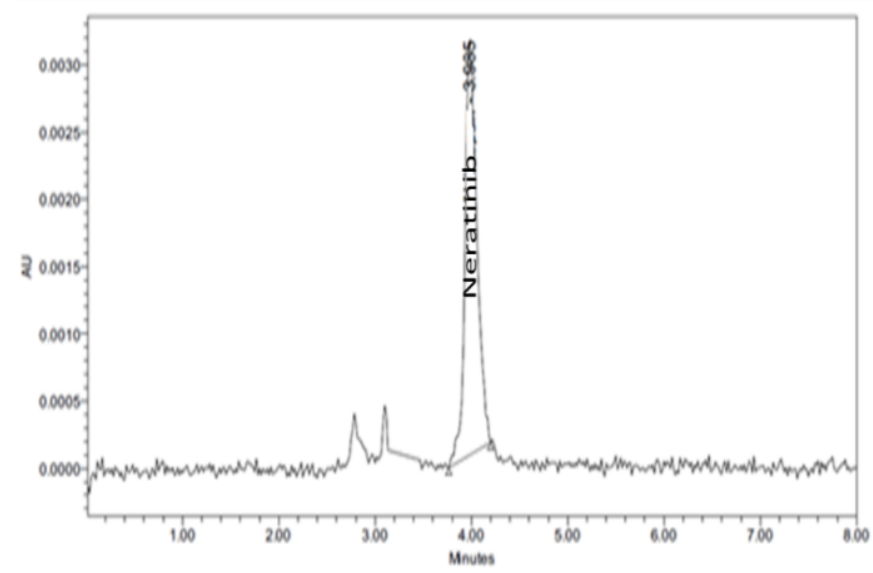

Fig. 7: LOQ Chromatogram of Neratinib

\section{Limit of Detection (LOD) and Limit of Quantification (LOQ)}

LOQ and LOD values for Neratinib were $0.43 \mathrm{ppm}$ and 1.31ppm respectively (Figure 6 and Figure 7).

\section{Accuracy}

The accuracy of developed method is determined for three concentration levels of $80 \%, 100 \%$ and $120 \%$ by recovery experiment. The results established by performing recovery studies on three replicates of three concentrations by adding known amount of Neratibin. Results found within the acceptable limit (Table 6).

\section{Robustness}

Six samples in each case analysed by altering flow rate, mobile phase composition and column temperature. The \%RSD in each case evaluated and results were within acceptable limits (Table7).

\section{DISCUSSION}

A simple, accurate and linear RP-HPLC method developed for estimation of Neratinib. The mobile phase comprises of buffer (potassium dihydrogen orthophosphate) and acetonitrile in the ratio of 60:40 (v/v) with $0.1 \%$ formic acid with retention time of 4.001 min. The developed method was validated for various parameters as per ICH guidelines. The linearity of developed method was established for concentration of $30-180 \mu \mathrm{g} / \mathrm{ml}$ with regression coefficient value of 0.9998 indicating high precision of the method. The system suitability data are within the acceptable limit. The percentage assay of Neratinib was $99.76 \%$ indicating non-interference of the common excipients used in the formulation. The limit of detection (LOD) and limit of quantification (LOQ) for Neratinib were $0.43 \mathrm{ppm}$ and 1.31 ppm respectively.

\section{REFERENCES}

1. Minami $Y$, Shimamura $T$, Shah $K$, LaFramboise $T$, Glatt KA, Liniker E, Borgman CL, Haringsma HJ, Feng W, Weir BA, Lowell AM, Lee JC, Wolf J, Shapiro GI, Wong KK, Meyerson M, Thomas RK. The major lung cancer-derived mutants of ERBB2 are oncogenic and are associated with sensitivity to the irreversible EGFR/ERBB2 inhibitor HKI272. Oncogene. 2007;26(34):5023-7.

2. Krishnan S, Miller RM, Tian B, Mullins RD, Jacobson MP, Taunton J. Design of reversible, cysteine-targeted Michael acceptors guided by kinetic and computational analysis. J Am Chem Soc. 2014;136(36):12624-30.

3. Singh J, Petter RC, Baillie TA, Whitty A. The resurgence of covalent drugs. Nature reviews. Drug discov. 2011;10(4):30717.

4. Kwak E. The role of irreversible HER family inhibition in the treatment of patients with non-small cell lung cancer. The oncologist. 2011;16(11):1498-507,

5. Bose P, Ozer H. Neratinib: an oral, irreversible dual EGFR/HER2 inhibitor for breast and non-small cell lung cancer. Expert Opin Investig Drugs. 2009;18: 1735-1751.

6. Tanveer AW, Ahmed HB, Abounassif MA, Zargar S. Study of Interactions of an Anticancer Drug Neratinib with Bovine Serum Albumin: Spectroscopic and Molecular Docking Approach. Front Chem. 2018; 6: 47.

7. Chandrasekaran A, Shen L, Lockhead S, Oganesian A, Wang J, Scatina J. Reversible covalent binding of neratinib to human serum albumin in vitro. Drug Metab Lett. 2010; 4(4):220-7.

8. Maher H. Development and validation of a stabilityindicating HPLC-dad method with ANN optimization for the determination of diflunisal and naproxen in pharmaceutical tablets. Journal of Liquid Chromatography \& Related Technologies 2014; 37(5):634-652.

9. Tanveer AW, Seema Z, Ajaz A. Ultra Performance Liquid Chromatography Tandem Mass Spectrometric Method Development and Validation for Determination of Neratinib in Human Plasma. S Afr J Chem. 2015:6893-98.

10. Abbas R, Hug BA, Leister C, Burns J, Sonnichsen D. Pharmacokinetics of oral neratinib during co-administration of ketoconazole in healthy subjects. Br J Clin Pharmacol. 2011; 71: 522-527.

11. Brian FK, Robert AP, Alvin W, Kiana K, Samuel J, Jan HB. LC-MS/MS assay for the quantitation of the tyrosine kinase 
M Lakshmi Kanth et al. / Development and Validation of RP-HPLC for Estimation of Neratinib

inhibitor neratinib in human plasma. J Pharm Biomed Anal. 2017; 134: 130-136.

12. Afnan HZ, Nehal NK, Sundus AI, Wafaa NA, Maher HM Micelle-enhanced direct spectrofluorimetric method for the determination of linifanib: Application to stability studies. Luminescence. 2017; 32(7):1162-1168.
13. Dong Q. Determination of Neratinib Tablets by HPLC. Food and Drug.2016;4: 280-282.

14. International Conference on Harmonization, ICH Guidelines, Validation of Analytical Procedures Technical Requirements for Registration of Pharmaceuticals for Human Use: Text and Methodology Q 2 (R1), International Conference on Harmonization, Geneva, Switzerland, November 2005.

HOW TO CITE THIS ARTICLE: Lakshmi Kanth M, Raj Kamal B. Development and Validation of RP-HPLC for Estimation of Neratinib in Bulk and Tablet Dosage Form. Int. J. Pharm. Sci. Drug Res. 2019; 11(2): 56-60. DOI: 10.25004/IJPSDR.2019.110202 